\title{
DEMONSTRATION OF A HERPES-TYPE VIRUS IN SHORT-TERM CULTURED BLOOD LYMPHOCYTES ASSOCIATED WITH MAREK'S DISEASE
}

\author{
J. G. Campbell and G. N. Woode \\ British Empire Cancer Campaign for Research Unit, Poultry Research Centre, Edinburgh, \\ and Department of Veterinary Pathology, Royal (Dick) School of Veterinary Studies, \\ University of Edinburgh
}

\section{Plates XXXVIII-XLVIII}

MAREK's disease (Marek, 1907) is an infectious lymphoproliferative disorder of chickens characterised by neural infiltration with lymphocytes and plasma cells, by visceral lesions and by uveitis.

The neural form is most frequent, but all forms may occur either separately or in any combination. The visceral and, occasionally, the neural forms of the original, or classical, type of disease are characterised by tumours that appear, at any rate initially, to be of an inflammatory nature and have been termed lymphogranulomas (Campbell, 1956). These may subsequently undergo malignant transformation to form lymphoblastomas. An acute form has appeared in the last decade, which from its onset shows a much higher incidence of malignant tumours involving viscera, subcutaneous tissue and nerves.

This relatively new and highly infectious disease has been the subject of intensive research in recent years, and a strongly cell-associated, herpes-type virus, possibly belonging to sub-group $\mathrm{B}$, has been regularly isolated and is considered to be the likely cause (Churchill and Biggs, 1967, 1968; Epstein et al., 1968; Nazerian et al., 1968; Solomon et al., 1968). The methods employed by these workers involved the establishment of healthy monolayer cultures of chick kidney cells, or chick or duck embryo fibroblasts, and their subsequent infection with material from experimentally maintained strains of the disease or from field cases. Usually, prolonged culture and serial passage were necessary before a visible cytopathic effect was produced and virus was demonstrable by electron microscopy. Acute Marek's disease is readily transmitted by the inoculation of whole blood into young chicks, although some lines of fowls are more susceptible than others. Cell-free plasma has proved to be less effective as an inoculum than whole blood (Biggs and Payne, 1967; Witter, Burgoyne and Solomon, 1968; Glaser et al., 1969), but the formed element in the blood that carries the infective agent has not been identified. The more chronic, classical form of the disease has been equally intensively investigated since it was first described by Marek. It is a disease difficult to transmit experimentally and its aetiology, although presumptively similar to that of the acute form, remains unestablished.

The present paper reports a method that makes possible the rapid detection of intranuclear, herpes-type virus in "blast"-like, transformed lymphocytes from the blood in both the classical and acute forms of Marek's disease, by employing a short-term tissue-culture method adapted from the simple standard technique used in chromosomal analysis of blood. Cells containing naked and coated virus are readily obtained, and are very suitable for the study of viral

Received 11 Sept. 1969; accepted 4 Dec. 1969.

J. MED. MICROBIOL.-VOL. 3 (1970) 
replication, for studies of infection in vitro and possibly also in vivo, and for immunological investigations.

\section{MATERIALS AND METHODS}

\section{Chickens}

The chickens were mostly derived from the Edinburgh Poultry Research Centre's flock of Brown Leghorns, line B, in which classical Marek's disease is endemic. Material from acute field cases and experimentally infected cases was obtained from $\mathrm{Dr}$ J. E. Wilson, Veterinary Laboratory, Ministry of Agriculture, Fisheries and Food, Lasswade, Midlothian, who also arranged for us to collect blood samples from a small flock of fowls reared in isolation and in which no Marek's disease had occurred in the parent stock and the first generation progeny during $15 \mathrm{mth}$.

\section{Collection of lymphocytes}

Lymphocytes for culture were obtained from both affected and clinically normal chickens by withdrawing $10 \mathrm{ml}$ blood from the brachial vein into a heparinised syringe and transferring it to a centrifuge tube containing $\mathbf{0 . 2} \mathrm{ml}$ phytohaemagglutinin. The blood was allowed to stand at room temperature for $1-2 \mathrm{hr}$ and then centrifuged for $10-12 \mathrm{~min}$. at $130 \mathrm{~g}$. Plasma with suspended cells was transferred with a pasteur pipette to another tube and centrifuged at $640 \mathrm{~g}$ for $10-15 \mathrm{~min}$. After the supernatant plasma had been removed, the cell pellet was washed twice with phosphate-buffered saline $\left(\mathrm{NaCl} 8.5 \mathrm{~g}, \mathrm{Na}_{2} \mathrm{HPO}_{4} 1.07 \mathrm{~g}\right.$, $\mathrm{NaH}_{2} \mathrm{PO}_{4} .2 \mathrm{H}_{2} \mathrm{O} 0.39 \mathrm{~g}$, and water 1 litre, $p \mathrm{H} \mathrm{7.1)}$ centrifuged, and finally resuspended in $2 \mathrm{ml}$ foetal bovine serum. The cells, when examined by phase-contrast, were seen to be mostly lymphocytes with some monocytes. In later modifications of the method, which gave marginally better results, the blood was withdrawn into a syringe containing $1 \mathrm{ml}$ of 3.8 per cent. sodium citrate and the phytohaemagglutinin was added to the complete culture prior to incubation.

\section{Culture of lymphocytes}

Growth medium consisted of Eagle's Minimal Essential Medium (Flow Laboratories) containing penicillin 100 units per $\mathrm{ml}$ and streptomycin $100 \mu \mathrm{g}$ per ml, supplemented by the addition of $0.3 \mathrm{ml}$ of 5 per cent. glutamine and $0.1 \mathrm{ml}$ of 10 per cent. sodium bicarbonate per $100 \mathrm{ml}$. The 2-ml volume of lymphocyte suspension in foetal bovine serum was added to $8 \mathrm{ml}$ of the supplemented Minimal Essential Medium, giving a final concentration of 20 per cent. serum in the medium. Incubation was at $37^{\circ} \mathrm{C}$ and was done in 25 -ml screwcapped glass bottles or in Falcon plastic tissue-culture bottles (Falcon Plastics, Los Angeles, California; Agents: Townson and Mercer Ltd, Edinburgh). The bottles were either gassed individually with a mixture of 5 per cent. $\mathrm{CO}_{2}$ in air and then tightly stoppered, or incubated with loose stoppers in the $\mathrm{CO}_{2}$-air mixture in double-tapped Perspex boxes containing a dish of phenol-red indicator, which provided humidity and a check on atmospheric $p \mathrm{H}$. Falcon bottles were incubated flat or slightly inclined, and glass bottles were incubated upright. Cultures were usually maintained for periods of about $72-90 \mathrm{hr}$, with extremes of $65-165 \mathrm{hr}$.

\section{Electron microscopy}

After incubation the cells were resuspended, transferred to a centrifuge tube and spun at $640 \mathrm{~g}$ for $10 \mathrm{~min}$. The medium was discarded and the cells were washed twice with phosphatebuffered saline and centrifuged. After the supernatant fluid had been decanted, about $5 \mathrm{ml}$ of 5 per cent. glutaraldehyde in phosphate-buffered saline $(p \mathrm{H} \mathrm{7 \cdot 1)}$ was carefully pipetted on to the packed cells. Fixation was for $1 \mathrm{hr}$, after which the pellet was washed in three successive changes of phosphate-buffered saline, post-fixed for $1 \mathrm{hr}$ in 2 per cent. osmium tetroxide and processed for embedding in Araldite. Sections were cut with an LKB ultramicrotome and stained with uranyl acetate and lead citrate. They were examined with a Philips EM300 electron microscope. 


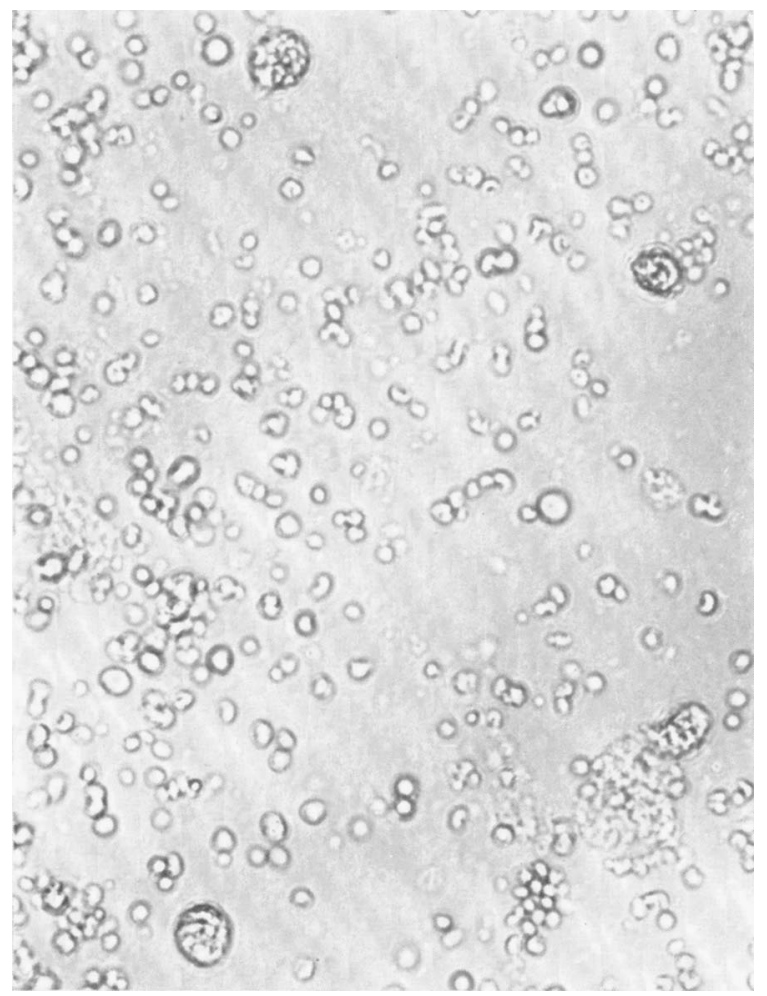

FIG. 1.- " Rosette" formation, or satellitosis of lymphocytes in a 72-hr culture of blood lymphocytes from a case of classical Marek's disease. Phase contrast. $\times 320$. 


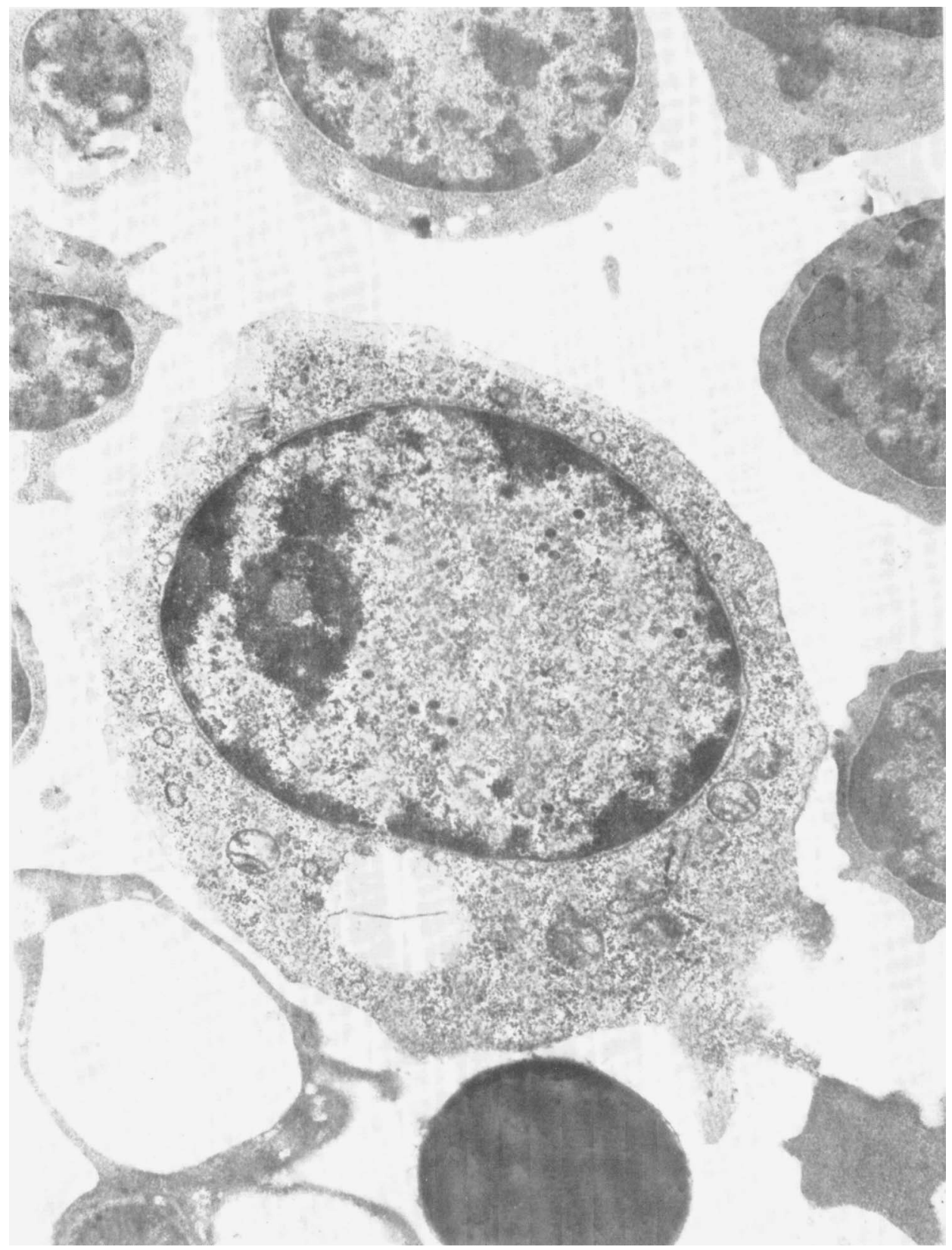

Fic. 2.-Transformed lymphocyte with intranuclear virus particles, from a 72-hr culture of lymphocytes from a case of classical Marek's disease. The large size and marginated chromatin allows rapid identification of infected cells at low magnification. Electron micrograph (EM). $\times 16,190$. 
Herpes-TyPe VIRUS ANi MAREK`S DISEASE

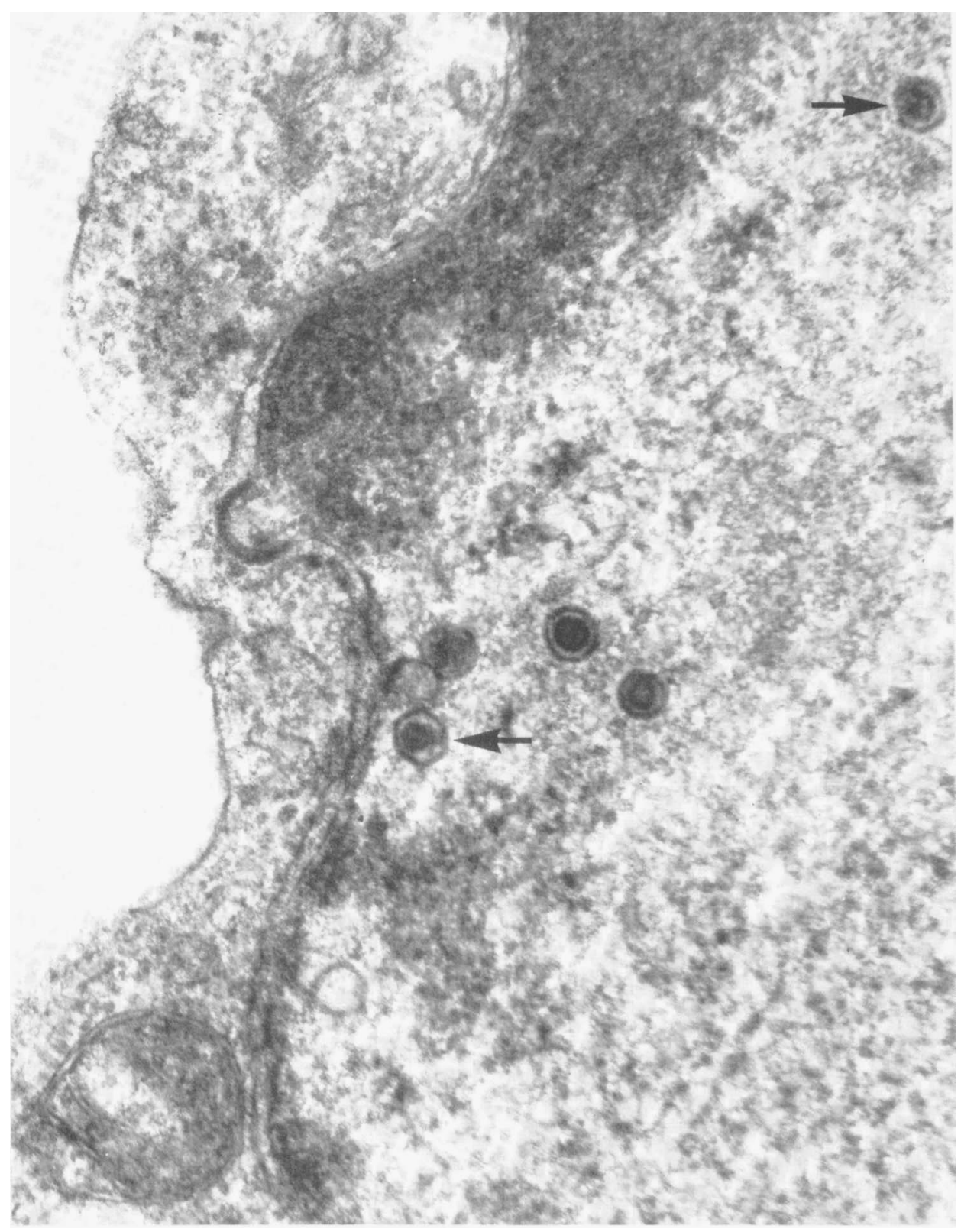

FIG. 3.- Intranuclear immature herpes-type particles in a cultured transformed lymphocyte from a case of classical Marek's disease. Note hexagonal profile and variably dense nucleoid (arrows), also an outpocketing of the irregular nuclear membrane. EM. $\times 79,800$. 


\section{Light microscopy and immunofluorescence}

Films of cultured lymphocytes and flying coverslip preparations of infected kidney monolayers were stained with methyl green-pyronin (Kurnick, 1955) or haematoxylin and eosin for conventional microscopy, and with coriphosphine $\mathrm{O}$ by the method of Keeble and Jay (1962) for fluorescence microscopy.

Antisera for immunofluorescence. These antisera were derived either from chickens experimentally infected with acute Marek's disease and kindly donated by Dr P. M. Biggs, or from animals with naturally occurring infections of the classical form, some of which, in an effort to boost antibody, had received repeated intramuscular injections of blood from classical cases, plus Freund's complete adjuvant.

Immunofluorescence method. The indirect, or double layer, method was used for immunofluorescence studies. Monolayers and smears were washed gently in three changes of phosphate-buffered saline, dried at $37^{\circ} \mathrm{C}$ for $1 \mathrm{hr}$, fixed for $10 \mathrm{~min}$. in acetone, and dried in an incubator. All preparations were processed immediately. The first layer of reagent applied was a 1 in 10 dilution of homologous antiserum in phosphate-buffered saline. It was allowed to act for $30 \mathrm{~min}$. in a moist chamber. Control preparations were treated with normal serum or infectious laryngotracheitis antiserum (kindly given by Mr A. J. MacLeod, The Wellcome Foundation Ltd) in place of serum from Marek's disease. The preparations were washed with constant stirring for $1 \mathrm{hr}$ in a large volume of phosphate-buffered saline and then stained for $30 \mathrm{~min}$. with the second layer of reagent, which consisted of a 1 in 10 dilution of horse anti-chicken gamma-globulin tagged with fluorescein isothiocyanate (Progressive Laboratories Inc., Baltimore) in phosphate-buffered saline, again in a moist chamber. After being washed for at least $1 \mathrm{hr}$ as before, the preparations were mounted in a 90 per cent. solution of glycerol in phosphate-buffered saline and examined for fluorescence excitation under ultraviolet radiation in a Zeiss photomicroscope with a phase-contrast fluorescence condenser, exciter filter $\mathrm{BG} / 12$ and barrier filter 50 .

\section{Tissue culture}

Chicken kidney cells were cultured by the method of Churchill (1965) modified by the substitution of a culture medium that gave better results than either Churchill's medium or that of Kawamura, Isogai and Tsubahra (1961). The growth medium consisted of Hanks' Salt Solution (Burroughs Wellcome and Co.) with 0.5 per cent. lactalbumin hydrolysate (V. A. Howe and Co.), 10 per cent. calf serum, $0 \cdot 044$ per cent. sodium bicarbonate, penicillin 100 units per $\mathrm{ml}$, and streptomycin $100 \mu \mathrm{g}$ per $\mathrm{ml}$. For maintenance, a similar medium containing 2 per cent. calf serum and 0.088 per cent. sodium bicarbonate was used.

Cell monolayers on glass were confluent in 3-5 days, and were maintained satisfactorily for up to $12 \mathrm{wk}$. Cultures from birds aged 3-12 wk required an inoculum of $8 \times 10^{5}$ viable cells per ml, and those from birds aged 13-16 wk required one of $1.6-3 \times 10^{6}$ cells per ml. The age of the bird did not appear to influence the quality of the culture produced. The calf serum was filtered through a Sartorius membrane filter with a pore size $0 \cdot 2 \mu \mathrm{m}$. It was not heat-treated at $56^{\circ} \mathrm{C}$, since such heating had been found to be deleterious for the growth of cells.

\section{RESULTS}

\section{Lymphocyte cultures}

Optimum survival with cell transformation to a " blast" form was obtained with 72-96 hr cultures, although on one occasion transformed cells were seen at $48 \mathrm{hr}$. Usually the lymphocytes tended to degenerate when incubation was prolonged to more than $144 \mathrm{hr}$, although one culture showed excellent survival at $165 \mathrm{hr}$. Prolonged culture was possible, since in one instance lymphocytes from a healthy control were maintained through 11 changes of growth medium 
during a period of $5 \mathrm{wk}$, in the course of which they underwent conversion to a slowly growing syncytium of histiocyte-like cells.

At $24 \mathrm{hr}$, cultures almost always showed "satellitosis" of lymphocytes around a larger macrophage-like cell. These clumps increased in size and eventually formed conspicuous " rosettes" (fig. 1).

Electron-microscope appearances. About 4 per cent. of the cultured lymphocytes transformed into "blast" cells. These transformed cells, taken from birds subsequently shown to have suffered from acute or classical Marek's disease, were easily recognisable, being 2-4 times the size of unaltered lymphocytes (fig. 2). They had an increased cytoplasm: nucleus ratio, large, often irregular-shaped, vesicular nuclei, marginated chromatin and, occasionally, disruption of the nuclear membrane. Typical, hexagonal herpes-type virus particles, similar to those described by Epstein et al. and Nazerian et al., were present in many of the transformed cells. The majority were immature, having a single envelope surrounding a nucleoid of variable density, and measured $94 \times 74 \mathrm{~nm}$ in diameter (fig. 3). Empty and double-enveloped particles were occasionally seen, although the latter only rarely. They measured $120 \mathrm{~nm}$ in diameter and sometimes were seen within vesicles in the nucleoplasm (fig. 4). In some cases, aggregates of particles, about $38 \mathrm{~nm}$ in diameter and resembling naked nucleoids, appeared to be developing within the nucleus from a localised "cloud" of fine granular material (fig. 5). Budding of virus through the nuclear membrane was not observed, although suggestive outpocketings were occasionally seen (fig. 3). Cytoplasmic particles were not observed.

Two cultures showed, in addition to cells containing formed virus, a few cells whose nuclei contained long double-walled tubules about $74 \mathrm{~nm}$ in width. The inner walls of the tubule showed traces of beading and measured $35 \mathrm{~nm}$ in diameter. They invested a central, less dense core, which was occasionally exposed as a thread about $22 \mathrm{~nm}$ thick. These tubular structures were invariably associated with single-enveloped virus particles and, where they were cut across, were obviously similar in structure to the latter (fig. 6).

In a number of other cultures, cells that were possibly monocytes were found to contain linear arrays in the cytoplasm. These arrays were composed of pairs of rather ill-defined membranes $37 \mathrm{~nm}$ apart, which invested a double row of particles spaced at $15 \mathrm{~nm}$ intervals. Each doublet enclosed an electronlucent core about $10 \mathrm{~nm}$ in diameter. Parallel arrays produced a pattern resembling a tyre-track, and often traversed practically the whole width of a cell, deeply dividing the nucleus in the process (fig. 7). The membranous component was more prominent when bundles of arrays were cut tangentially. Some "tracks" appeared to be within the nucleus, but were in fact lying in deep invaginations of the nuclear membrane (fig. 8). Sheets of similar structures were observed in the cytoplasm of a kidney cell from an infected monolayer (fig. 9).

Unlike the tubular structures, these "tyre-tracks" were never found in transformed cells, although other transformed cells in the same culture contained herpes-type particles. Other notable features were the frequent 
proximity of centrosomes to the "tyre-tracks" and the occasional occurrence, pointed out to us by Mr M. Maxwell, of " tyre-tracks" in fresh, uncultured cells from certain clinically normal birds from the same flock. These birds are being further investigated for the presence of virus in cultured lymphocytes. A few clinically normal birds, belonging to the group in which Marek's disease was endemic, were observed to have virus in transformed cultured lymphocytes. In those cases in which further samples of lymphocytes were cultured, virus was again demonstrated. One bird was studied over a period of $12 \mathrm{mth}$ and its lymphocytes were cultured on six occasions. Virus was observed each time. Serum from this bird contained antibodies to the Marek's disease antigen as demonstrated by indirect immunofluorescent staining of infected cultures, and virus was isolated from the lymphocytes in cultures of uninfected chicken kidney tissue. At the time of writing, this bird remains clinically normal.

Virus was not found in cultured lymphocytes from a number of birds which, though thought to be suffering from Marek's disease, failed to provide evidence of infection on post-mortem examination.

Cytochemical and immunological tests. Transformed lymphocytes stained with the fluorochrome, coriphosphine O (G. T. Gurr, Ltd), gave positive reactions for nuclear DNA in the cytoplasm. This was supported by the results of applying the methyl green-pyronin method of Kurnick. The indirect immunofluorescence test performed with sera from chicks naturally or experimentally infected with Marek's disease, and suitably controlled, showed antigenic material in a proportion of transformed cells, and in the "rosettes". As with the cytochemical tests, the reactive component was situated not only within the nucleus, where it was either diffuse or particulate, but also diffusely within the cytoplasm (figs. 10 and 11). Positive results were obtained in tests in which the first application was done with antiserum either from the classical or the acute form of Marek's disease. Control tests were done by substituting sera from disease-free birds, or infectious laryngotracheitis antiserum, and gave negative results.

\section{Kidney cell cultures}

A cytopathic effect identical with that described by Churchill and Biggs (1967), Solomon et al., and Witter, Solomon and Burgoyne (1969), was produced by culturing kidney cells from birds in a flock endemically infected with classical Marek's disease. These monolayers showed cytopathic effects after culturing for 3-8 wk. Alternatively, whole blood, lymphocyte suspensions (fresh or cultured) from classical cases and tumour cells from acute Marek's disease were inoculated on monolayers of uninfected kidney cells. The tumour cells were prepared by the same method as used for the trypsinisation of the kidney cells.

The cytopathic effect produced by infection of a healthy monolayer was usually visible within $3 \mathrm{wk}$. It was a necrotic reaction, with microplaques steadily increasing in size and becoming surrounded by large refractile polykaryocytes. Long delicate cytoplasmic threads extended across the plaque (fig. 12). After passage of infected cells removed from the glass with $0 \cdot 1$ per 
cent. trypsin in a 1 in 5000 solution of versene, many plaques became apparent within 3-5 days at the third pass. The cytopathic effect observed in the culture of the kidney cells from birds already infected was somewhat different, in that there was less evidence of microscopic necrosis of the monolayer. Plaques of large round refractile polykaryocytes were seen apparently lying on the monolayer. These tended to disappear after 3-7 days, leaving a clean culture at the site, with or without the loss of continuity of the monolayer. On one occasion, the culture, after exhibiting one plaque at $3 \mathrm{wk}$, became free from plaques by 8 wk. After its establishment as a secondary culture, with production of a satisfactory monolayer, a typical cytopathic effect with extensive necrosis developed at 10 days, and there was complete destruction of the monolayer by 15 days. Electron microscopy showed many intranuclear particles.

Typical herpes (Cowdry's type-A) inclusions were present in many cells bordering the plaques, in polykaryocytes and in the isolated cells lying along the cytoplasmic threads that spanned the space produced by the cytopathic effect (fig. 13). These inclusions all fluoresced brightly, as for DNA, with coriphosphine $\mathrm{O}$, and indirect immunofluorescence tests showed that they contained antigens characteristic of Marek's disease (fig. 14).

\section{Discussion}

In previous electron-microscope studies of the tissues of birds suffering from Marek's disease, no herpes-type virus has been observed (Wight et al., 1967). However, Schidlovsky, Ahmed and Jensen (1969) saw a herpes-type virus in material freshly processed for electron microscopy; this virus was present in the cytoplasm of the epithelium of the proximal renal tubule, although no virus was found in adjacent invading lymphoid tumour cells. Virus-like particles have been observed in cytoplasmic vacuoles of uncultured lymphocytes and in plasma from cases of Marek's disease (Wight et al.; Glaser et al., 1969). They appeared to be RNA viruses, possibly belonging to the sarcomaleucosis group, and their role in Marek's disease is uncertain.

In our study, a herpes-type virus was observed in the nucleus in a proportion of transformed lymphocytes (" blast" cells) from proven cases of acute or classical Marek's disease, after 3-5 days' culture in vitro. Similarly, a virus was found in cultured lymphocytes from a few clinically normal birds from the same flock. These viruses were shown to be similar in morphology, antigenicity and nuclear staining properties to those isolated in cultures of chicken kidney tissue. The lymphocyte cultures were still infectious to chicken kidney tissue culture after several days' incubation.

Why the virus cannot be observed in uncultured material is not readily explicable. However, some observations made in vitro suggest that this lack of success may be due to failure to examine the right cells. Culture of lymphocytes in the presence of phytohaemagglutinin leads to transformation of a proportion of cells to " blast" cells. This process involves a period of intense synthesis of protein and nucleic acid followed by an increase in size of the cells to two to four times that of other lymphocytes. Similarly, in tissue-culture 
studies it appeared that passage of infective cells, or induction of a secondary culture, may be required for the virus associated with Marek's disease to become active and induce a cytopathic effect. Perhaps, in the latent stages of nonproliferating infected cells, the production of viral nucleic acid or viral protein is reduced or absent, and reappears only when the cells enter a stage of intense activity prior to mitosis. This would explain why monolayers appear to show recovery to primary infection, and why one monolayer, after 8 wk in culture, developed an extensive cytopathic effect 10 days after its establishment as a secondary culture.

There is no indication in what form the virus exists within the host. The transformed cells may have been infected at the time of sampling, or have become secondarily infected from another cell, such as a macrophage. The satellite phenomenon suggested that the central infected cell was a macrophage and that this was surrounded by small lymphocytes. Observations on poliovirus infection of transformed human lymphocytes indicate that monocytes are normally infected and lymphocytes become infected only after transformation (Willems, Melnick and Rawls, 1969). It is not known whether only those cells that are transformable possess the viral genome, but certainly no untransformed cultured lymphocytes demonstrated specific immunofluorescence. The reaction of these cells with chicken antiserum to Marek's disease implies that they possessed antigens that were foreign to the host and appeared to be identical with those carried by infected cells in chicken kidney tissue cultures.

In birds, there is firm evidence that there are two populations of lymphocytes, those dependent on the thymus and those dependent on the bursa of Fabricius. The former cells are concerned with rejection of grafts and the latter with the production of antibody and the development of delayed-type hypersensitivity (Glick, Chang and Jaap, 1956; Mueller, Wolfe and Meyer, 1960; Warner and Szenberg, 1964). Whether both types of lymphocytes can be transformed and demonstrate virus is not known. However, it has been reported that bursectomy and X-irradiation can ameliorate, but not completely prevent, Marek's disease, whereas thymectomy combined with irradiation has no effect. Further evidence for both a bursal and a thymic role in Marek's disease comes from the observation that affected birds have a defective humoral antibody response and a defective ability to reject skin grafts (Chubb and Churchill, 1968; Purchase, Chubb and Biggs, 1968; Biggs et al., 1969; Churchill, Payne and Chubb, 1969).

It is possible that the satellitosis of lymphocytes in cell cultures is a manifestation of an altered immunological response. The enlarged cell, which is the focus of this phenomenon, was shown to contain antigenic material by the indirect immunofluorescence test. Early "rosette" formation showed the presence of antigen in this type of cell only. Later stages showed fluorescence throughout the investing cells, indicating active spread or diffusion of antigenic material to the reacting lymphocytes. Whether the virus can complete its development in these cells is not known. It has proved difficult to establish whether rosettes form in cultures of lymphocytes from virus-free birds (Naspitz 
and Richter, 1968). Preliminary tests showed reduced rosette formation or none in 90-hr cultures of lymphocytes from a small number of chickens that were reared in isolation and were free from clinically apparent Marek's disease. One culture, however, did develop plentiful rosettes, and electron microscopy showed that herpes-type particles were present in transformed cells. It is interesting that this bird developed Marek's disease some 8 wk after transfer to other premises.

The characteristic infiltration of lymphocytes and plasma cells into peripheral nerves in the neural form of the disease could also be interpreted as an immunological response, perhaps to a basic protein liberated in the nerve as a result of the destruction of myelin by the infective agent. This destruction has been shown to take place before the infiltration with lymphocytes (Heald et al., 1964). Reports that neurilemmal cells show proliferative changes in Marek's disease (e.g., Sevoian and Chamberlain, 1964) indicate some form of participation by these cells. An auto-immune basis for Marek's disease is, moreover, suggested by the similarity of some types of nerve lesion to those described by Siller (1960) in his study of experimental allergic encephalomyelitis in chickens.

\section{Nature of the tubules and filamentous arrays}

The obvious similarity in morphology and dimensions of the cross-sections of the intranuclear tubular structures to free, single-enveloped virus particles, and their close association with the latter, leaves little doubt that they are a filamentous form of the herpes-type virus. Similar structures have been described in connexion with other herpes-viruses, notably those of infectious laryngotracheitis of chickens (Watrach, 1962) and those of the renal carcinoma of leopard frogs (Stackpole and Mizell, 1968).

The construction of an icosohedral capsid invested with capsomeres requires the manufacture by the infected cell of both hexagonal and pentagonal capsomeres, 12 of the latter being essential for the formation of the 12 vertices. If, through a coding defect, only hexagonal capsomeres are formed, then flat sheets or tubular structures will result. An even more abortive attempt to assemble virus in the cytoplasm may be represented by the "tyre-tracks". Their structure is basically similar to the inner portion of the tubular form of the virus, with reasonable agreement in the size of the various components. Fig. 15 represents an hypothetical reconstruction of the tubular form and shows how the inner part, divested of its outer coat, would present upon longitudinal median section an appearance similar to a "tyre-track". Comparable structures have recently been reported in the proximal renal tubule epithelial cells of several species of monkey by Bulger (1968). She describes them as "granulelamella complexes" and suggests they are arrays of ribosomes. Somewhat similar structures have been seen in the vascular endothelium of frogs (Stehbens, 1965), in taste-bud cells of rats (Farbman, 1967) and in the cortical cells of a human adrenal adenoma (Hoshino, 1969). These authors consider the structures to be essentially a ribosomal-lamellar complex, although they all mention the possibility that they may be of a viral nature. It may be significant that 
three of the animal species involved, man, monkeys and frogs, are all known to be commonly infected with herpes-type viruses.

It is difficult to correlate the presence of structures in the cytoplasm with the replication of a herpes-virus that appears to be confined to the nucleus. A possibly similar structure was observed in skin epithelial cells of chickens infected with fowlpox virus, which never occurred in cells lacking this virus. However, this structure was not considered to be involved in the morphogenesis of fowlpox virus and its presence could not be correlated with the virus replication cycle (Simpson, 1969). Apparently no attempt was made to exclude the possibility of the cells also being infected with Marek's disease virus.

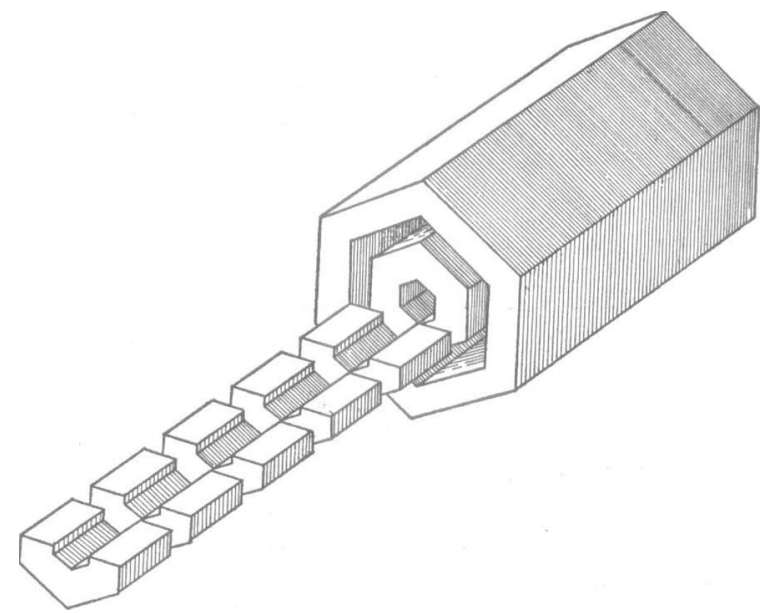

FIG. 15.-Hypothetical isometric drawing of the tubular or filamentous form of a herpes virus showing how, in the absence of the first envelope, the longitudinal section of the imperfectly replicated nucleoids would produce the appearance of a " tyre-track".

One other possible explanation of the arrays remains to be considered. Centrosomes have frequently been seen in their vicinity. Are the arrays aberrant cilia? Most non-ciliated cells are now known to have the potential to form cilia in abnormal conditions, but the structure of the arrays is so entirely different from that of cilia that it would be difficult to interpret them even as highly aberrant structures of that nature.

\section{SUMMARY}

Electron microscopy of short-term cultured blood lymphocytes from spontaneous cases of "classical" (neural) Marek's disease and some clinically normal chickens from the same flock showed a herpes-type intranuclear virus in a high proportion of transformed cells. In a few instances virus particles were closely associated with intranuclear filaments, which were thought to represent the product of aberrant viral replication. Some non-transformed cells showed granule-lamellar arrays in the cytoplasm, thought possibly to represent the inner structure of the filaments. 
The addition of cultured lymphocytes to healthy chick kidney monolayers induced a typical transmissible cytopathic effect associated with nuclear inclusions. Similar results were obtained using fresh lymphocytes, or tumour cells, from cases of the "acute" disease. A spontaneous cytopathic effect often developed in monolayers prepared from clinically normal chickens in a flock in which the disease was endemic.

Indirect immunofluorescence tests with either classical or acute Marek's disease antisera indicated the presence of viral antigen in a high proportion of transformed lymphocytes and in the kidney cells in the region of the cytopathic effect.

A herpes-type virus was also demonstrated in cultured transformed blood lymphocytes in cases of acute Marek's disease with gonadal tumours.

This investigation has been supported by the British Empire Cancer Campaign for Research. We would also like to thank Mr M. Maxwell for technical assistance, and Mr J. H. R. Campbell for preparing fig. 15.

\section{REFERENCES}

Biggs, P. M., ANd Payne, L. N. . 1967. J. Natn. Cancer Inst., 39, 267.

Biggs, P. M., Long, P. L., Kensy, S. G., 1969. Acta veterinaria, Brno, 38, 65. AND ROOTES, D. G.

BULGER, RUTH E.

1968. J. Ultrastruct. Res., 24, 150.

CAMpbell, J. G. .

1956. Vet. Rec., 68, 527.

Chubb R. C., ANd Churchill, A. E. - 1968. Ibid., 83, 4.

Churchill, A. E.

1965. Res. Vet. Sci., 6, 162.

Churchill, A. E., AND BigGs, P. M. 1967. Nature, Lond., 215, 528.

" " " " " . 1968. J. Natn. Cancer Inst., 41, 951.

Churchill, A. E., PAyne, L. N., AND 1969. Nature, Lond., 221, 744.

CHUBB, R. C.

Epstein, M. A., Achong, B. G., Chur- 1968. J. Natn. Cancer Inst., 41, 805. CHILL, A. E., AND BIGGS, P. M.

FARBMAN, A. I.

Glaser, R., Burke, C. N., Fredrickson,

T. N., AND LUGINBUHL, R. E.

Glick, B., Chang, T. S., AND JAAP, R. G.

Heald, P. J., Badman, H. G., Frunival,

B. F., AND Wight, P. A. L.

Hoshino, M.

Kawamura, H., Isogai, S., and TsubAHRA, $H$.

KeEBLE, S. A., AND JAY, R. F.

KURNICK, N. B. .

1967. J. Ultrastruct. Res., 19, 514.

1969. Avian Dis., 13, 261.

MAREK, J. . . . . . . . 1907. Dt. tierärztl. Wschr., 15, 417.

Mueller, A. P., Wolfe, H. R., AND 1960. J. Immun., 85, 172. MEYER, R. K.

NASPITZ, C. K., AND RICHTER, M.

1968. Prog. Allergy, 12, 1.

NAZERIAN, K., SOlomon, J. J., WitTer, R. L., AND BURMESTER, B. R.

Purchase, H. G., Chubb, R. C., AND 1968. J. Natn. Cancer Inst., 40, 583. BIGGS, P. M.

Schidlovsky, G., Ahmed, M., AND 1969. Science, N.Y., 164, 959. JENSEN, K. E. 
Herpes-type Virus and Marek's disease

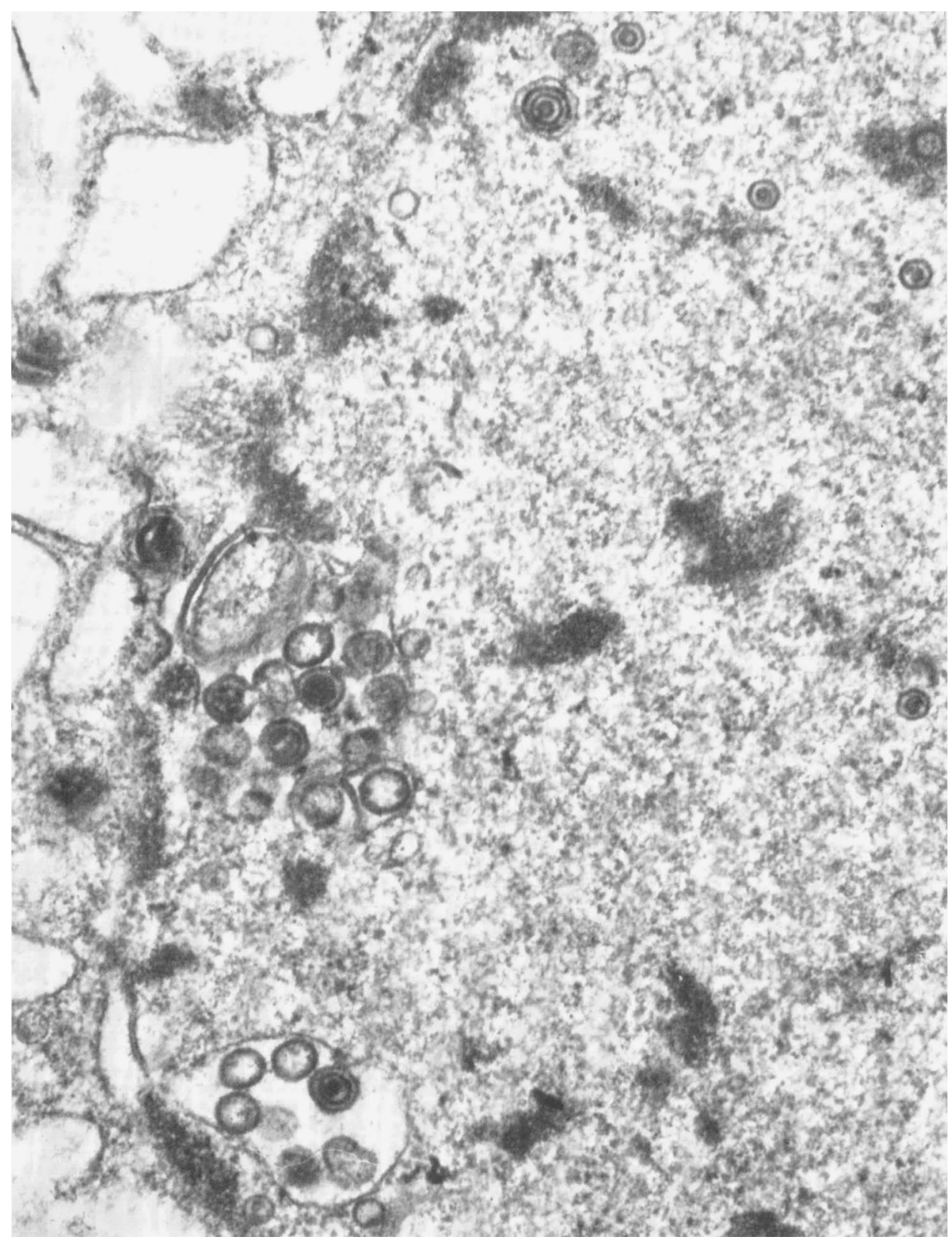

FIG. 4.-Groups of virus particles, some mature with double envelopes, in the nucleus of a disintegrating transformed lymphocyte from a case of classical Marek's disease. Some of the particles are within vacuoles. Empty immature hexagonal particles and what appear to be empty mature particles may be seen. EM. $\times 48,000$. 
HerPes-tyPe VIRUS AND MAREK's diseAse

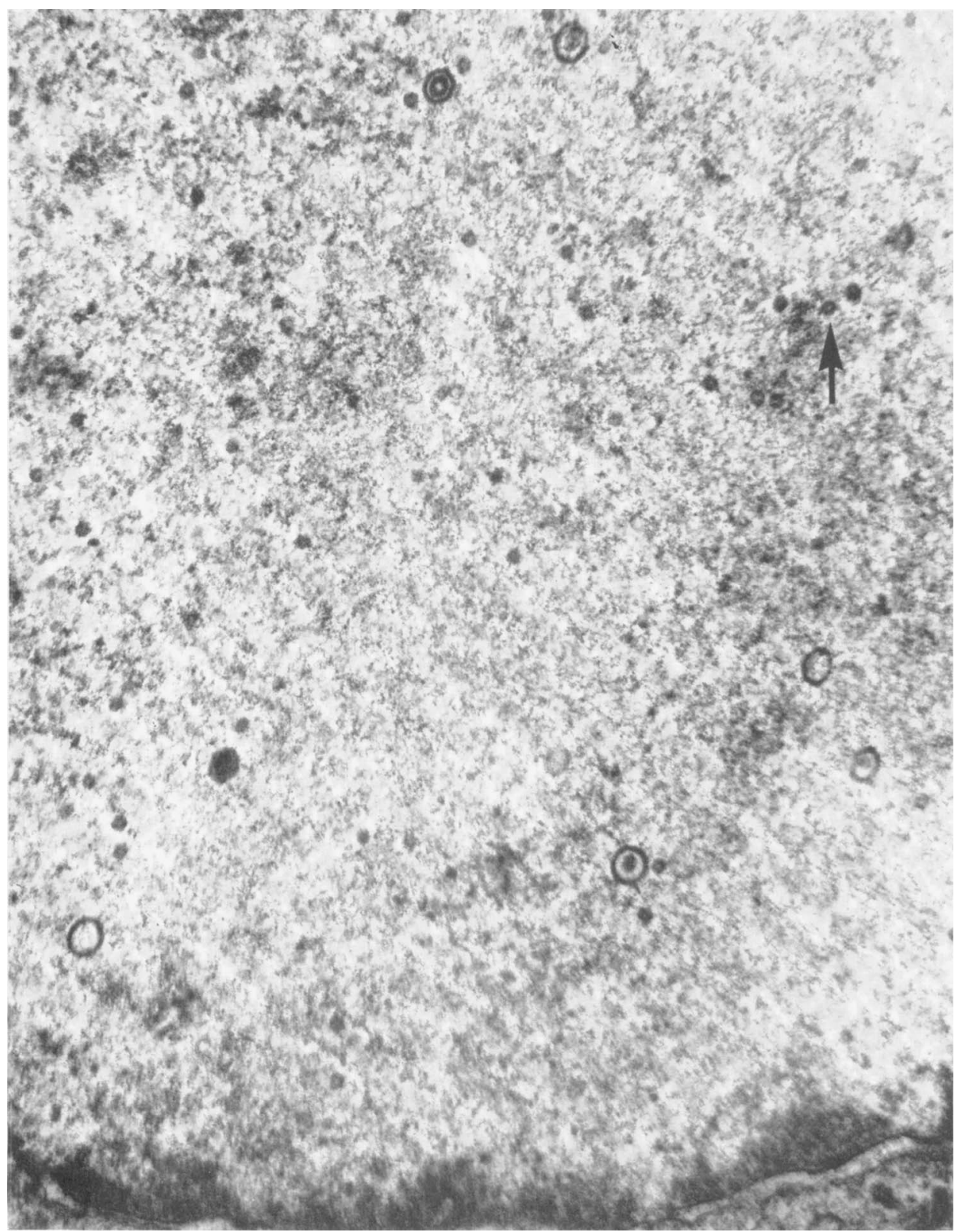

FIG. 5.- Naked (arrow) and immature virus particles apparently developing in a diffuse region of finely granular material in the nucleus of a transformed lymphocyte from a case of classical Marek`s disease. Two empty immature particles are also visible. EM. $\times 50,160$. 
HERPES-TYPE VIRUS AND MAREK'S DISEASE

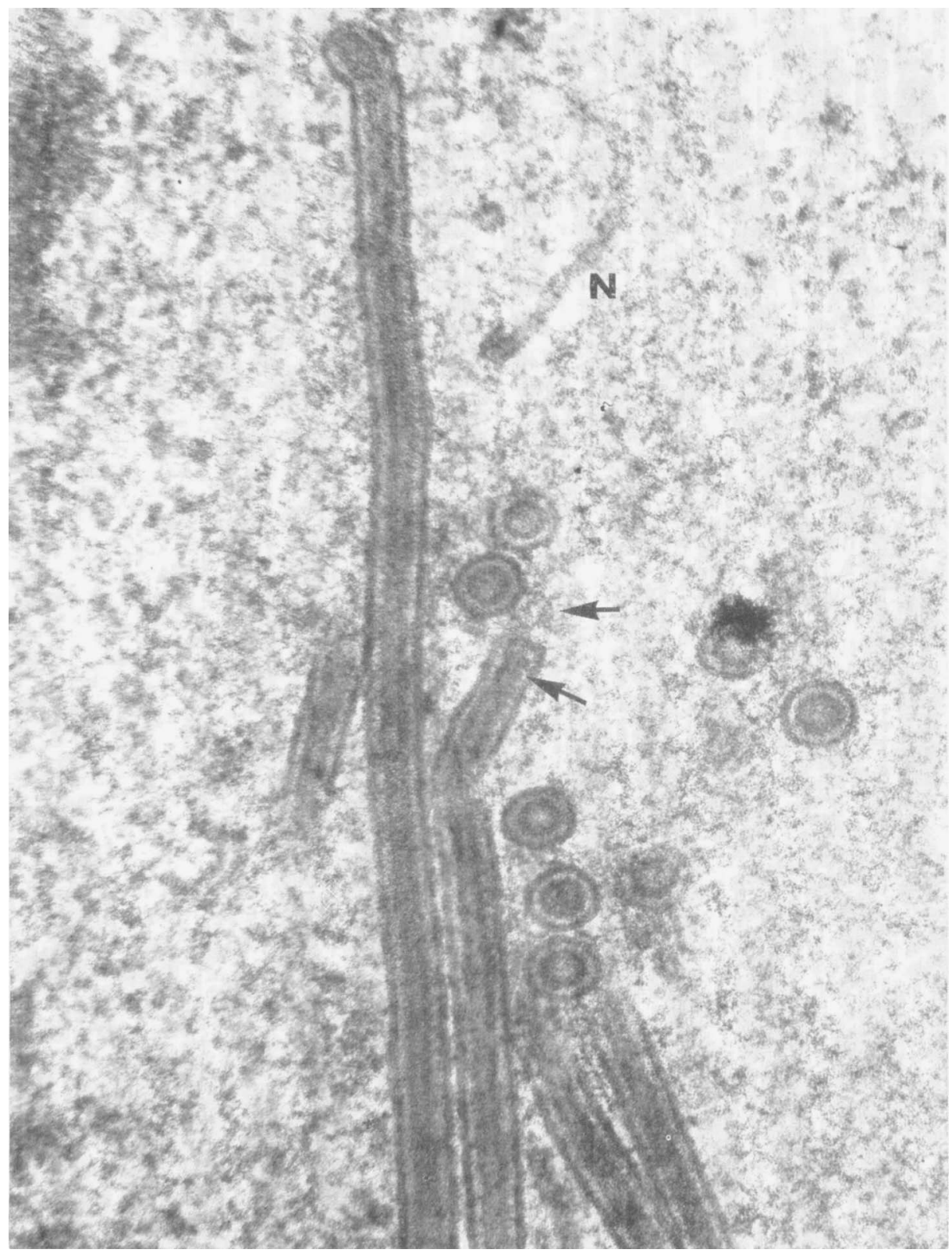

FIG. 6.-Double-walled filamentous structures intimately associated with immature particles in the nucleus of a transformed cell from a case of classical Marek's disease. A trace of regular beading is visible in the inner wall, and immediately adjacent is a faint hexagonal nucleoid (arrows). Note also a naked inner core (N). EM. x 96,000. 
HERPES-TYPE VIRUS AND MAREK`S DISEASE

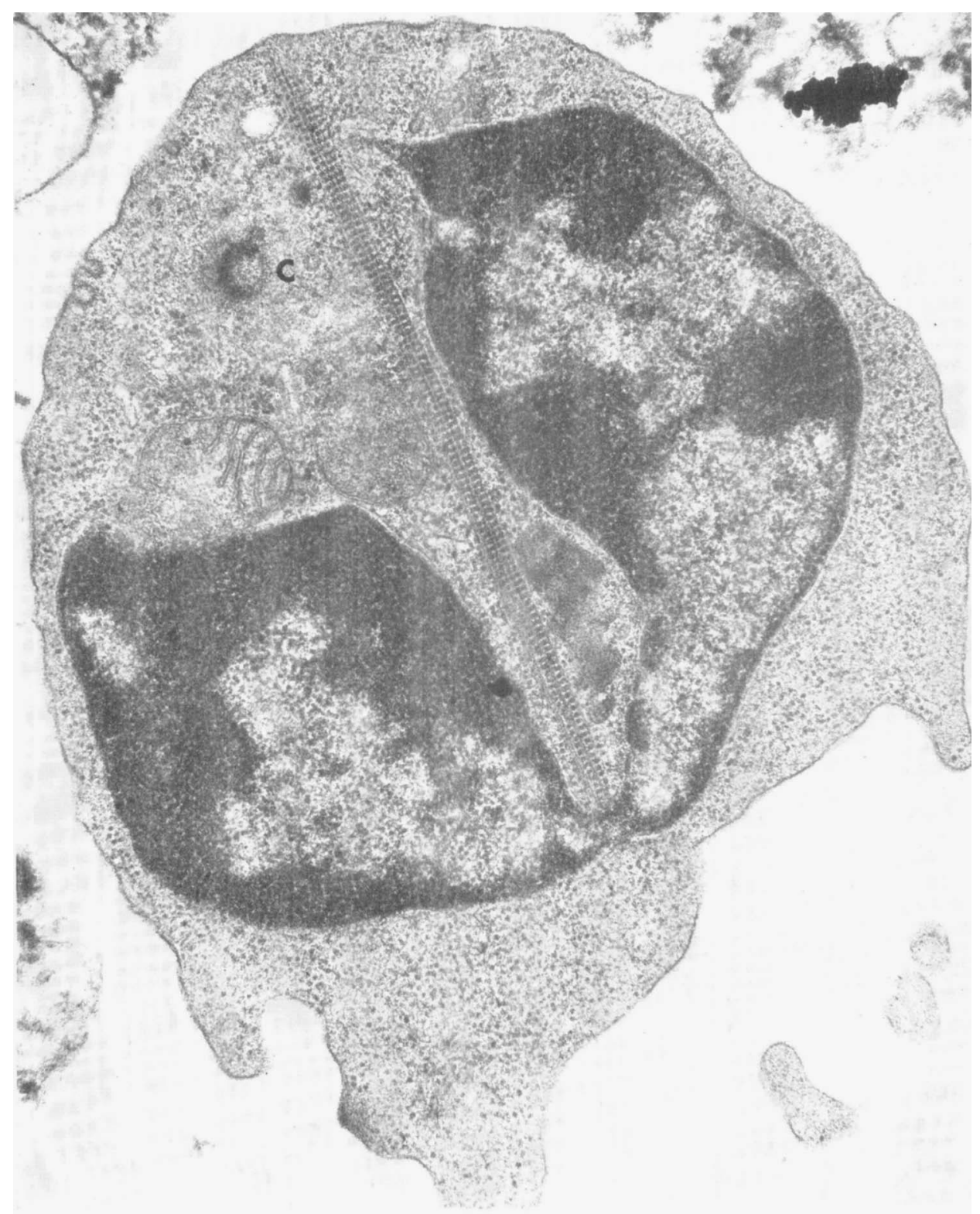

FIG. 7.-Parallel linear arrays ("tyre-track") in the cytoplasm of a large cultured cell from a case of classical Marek's disease, lying within a deep nuclear cleft. The nearby centrosome is indicated (C). EM. $\times 33,600$. 


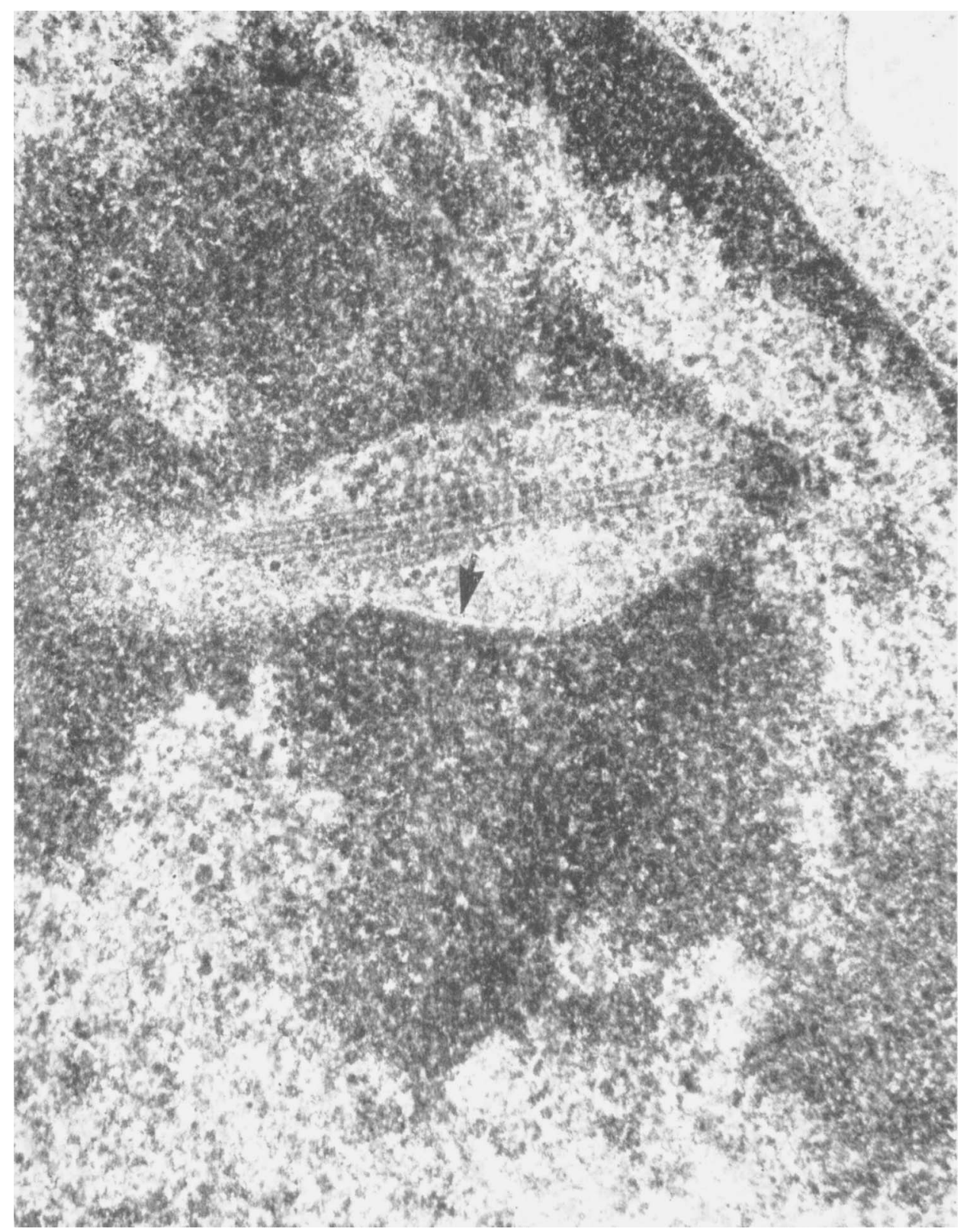

Fic. 8.-A "tyre-track" apparently lying within the nucleus of a transformed lymphocyte from a case of classical Marek's disease. Examination, however, shows it to be lying outside the deeply invaginated nuclear membrane (arrow). EM. $\times 79,800$. 
HERPES-TYPE VIRUS AND MAREK'S DISEASE

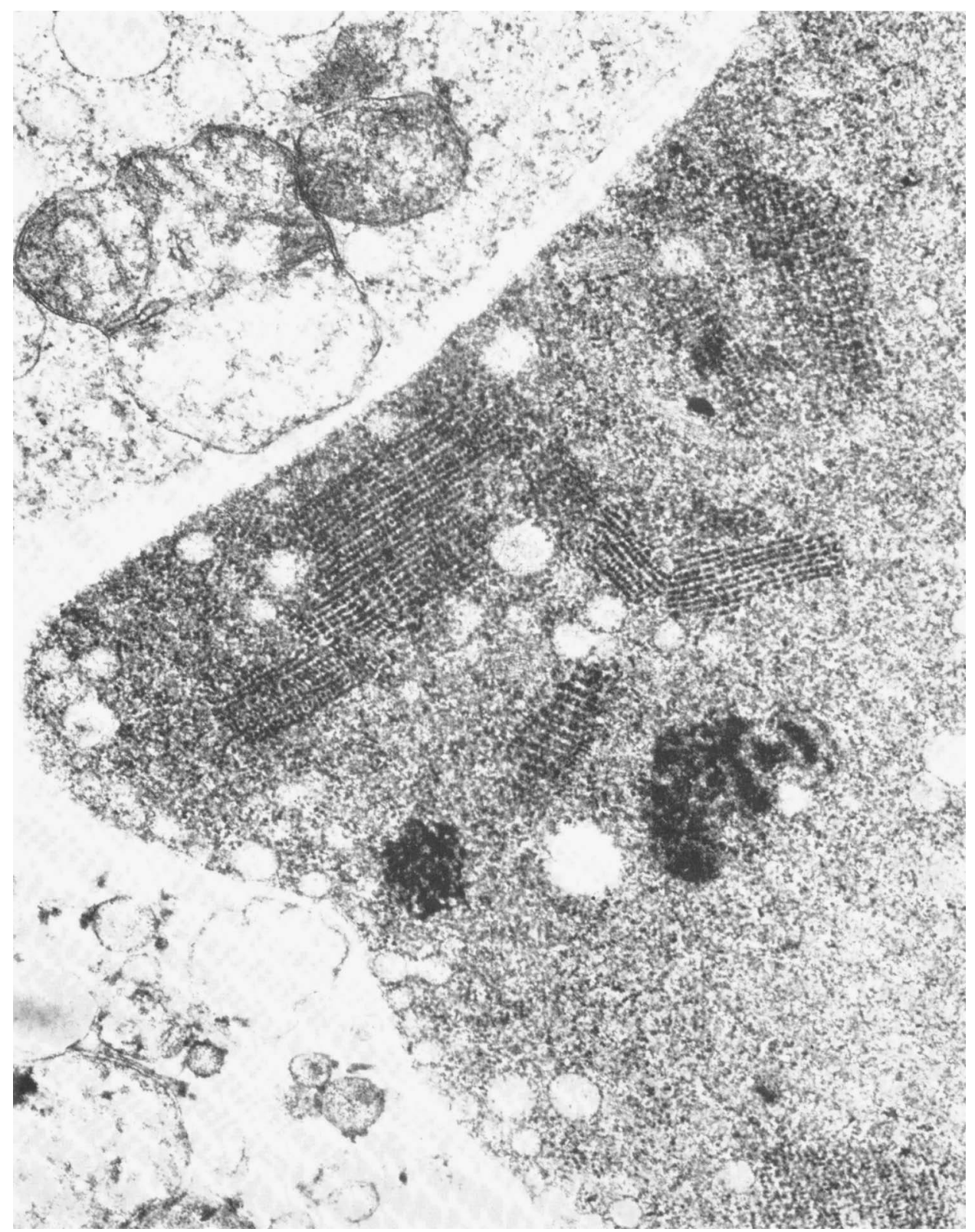

FIG. 9.- Sheets of linearly arranged particles in the cytoplasm of a chicken kidney cell grown in a tissue culture infected by exposure to cultured lymphocytes from a case of classical Marek's disease. EM. $\times 79,800$. 


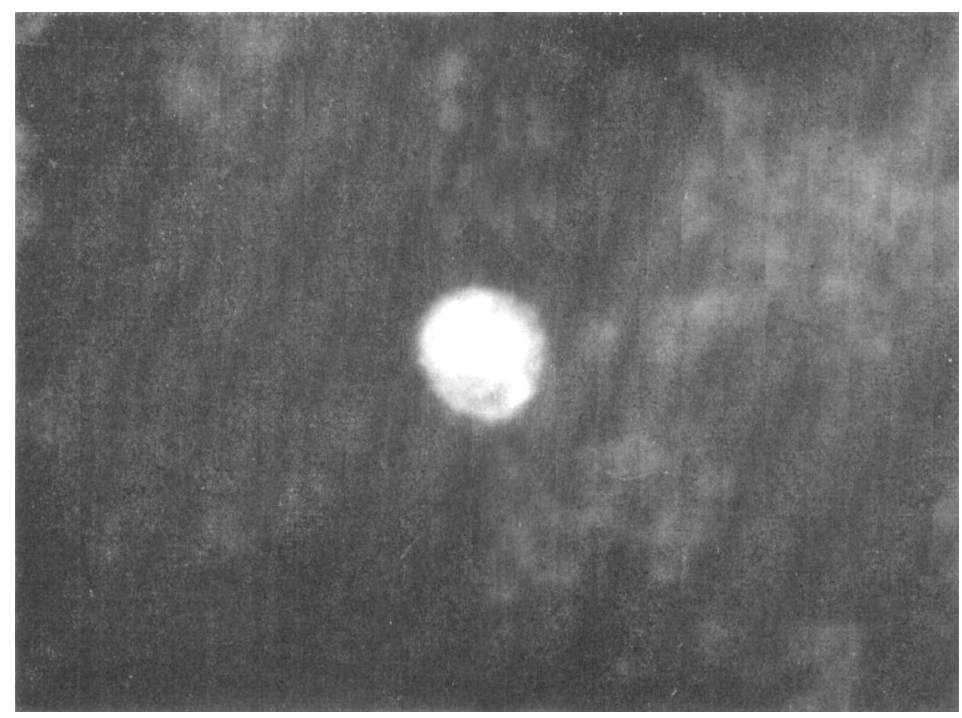

FIG. 10.-Specific immunofluorescence in nucleus and cytoplasm of a transformed lymphocyte from a case of classical Marek's disease, after exposure to homologous Marek's disease antiserum and treatment with horse anti-chicken- $\gamma$-globulin coupled with fluorescein isothiocyanate (FITC). Fluorescence microscopy (FM). $\times 1500$.

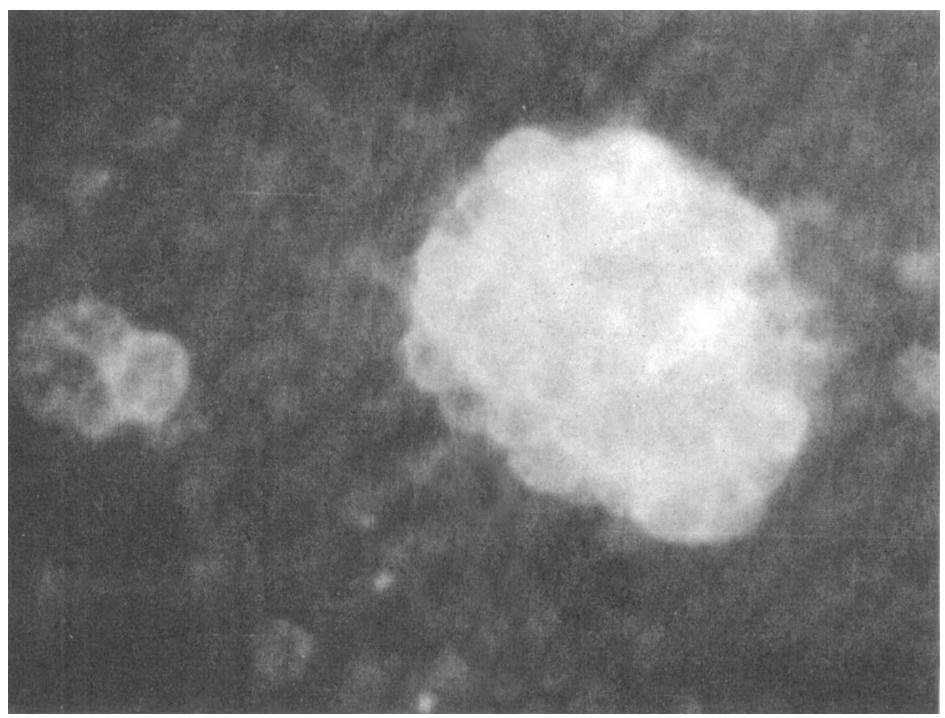

FIG. 11.-A " rosette" of lymphocytes cultured from a case of classical Marek's disease exhibiting immunofluorescence, and an early stage of satellitosis about a fluorescing cell to the left. Homologous antiserum, followed by horse anti-chicken- $\gamma$-globulin coupled with FITC. FM. $\times 1120$. 
Herpes-type virus and Marek's disease

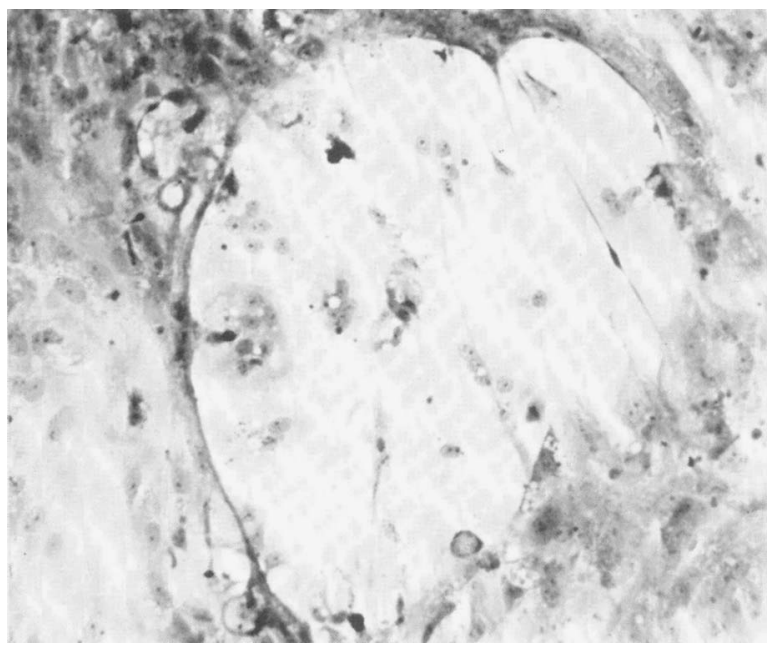

FIG. 12.-Fixed and stained preparation of a chicken kidney cell monolayer 3 wk after exposure to blood lymphocytes from a case of classical Marek's disease, showing a microplaque of cytopathic effect and associated polykaryocytes. Haematoxylin and eosin $(\mathrm{HE}) . \times 460$.

FIG. 13.-Characteristic Cowdry type-A inclusions in nuclei of chicken kidney cells 3 wk after exposure to blood lymphocytes from a case of classical Marek's disease, bordering a plaque in an infected monolayer. HE. $\times 1850$.
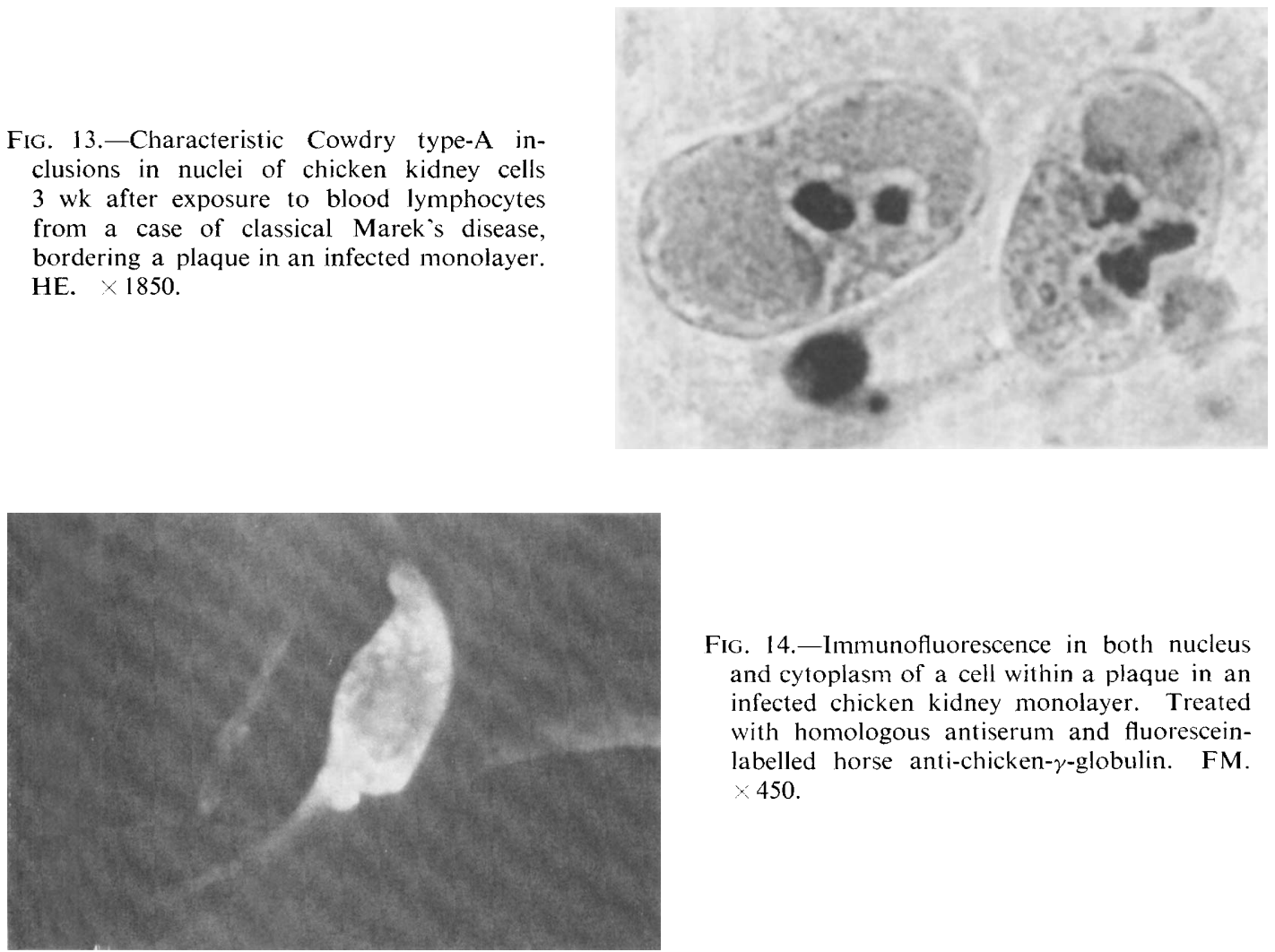

FIG. 14.- Immunofluorescence in both nucleus and cytoplasm of a cell within a plaque in an infected chicken kidney monolayer. Treated with homologous antiserum and fluoresceinlabelled horse anti-chicken- $\gamma$-globulin. FM. $\times 450$. 
Sevoian, M., and Chamberlain, D. M.. 1964. Avian Dis., 8, 281.

Siller, W. G. . . . . . . 1960. J. Path. Bact., 80, 43.

Simpson, C. F. . $\quad$. $\quad$. $\quad$. $\quad$. 1969. Avian Dis., 13, 89.

Solomon, J. J., Witter, R. L., Nazerian, 1968. Proc. Soc. Exp. Biol. Med., 127, 173.

K., AND BURMESTER, B. R.

StackPole, C. W., aNd Mizell, M. . 1968. Virology, 36, 63.

Stehbens, W. E. . . . . . 1965. Q.J. Exp. Physiol., 50, 375.

WARNer, N. L., AND Szenberg, A. . 1964. In Conference on the thymus, ed. by

R. A. Good and A. E. Gabrielsen, New York, Evanston and London, pp. 395413.

Watrach, A. M. $\quad$. $\quad$. $\quad$. $\quad$ 1962. Virology, 18, 324.

Wight, P. A. L., Wilson, J. E., CAMP- 1967. Nature, Lond., 216, 804. BeLl, J. G., AND FRASER, E.

Willems, F. T. C., MelniCK, J. L., AND 1969. J. Virol., 3, 451. RAWLS, W. E.

Witter, R. L., Burgoyne, G. H., AND 1968. Avian Dis., 12, $16 \%$. SOLOMON, J. J.

WITTER, R. L., SOlOMON, J. J., AND 1969. Ibid., 13, 101. Burgoyne, G. H. 